\title{
Potencial geoturístico do Semiárido paraibano: um estudo acerca do município de Cabaceiras/PB
}

\author{
Potential geoturistico semi-arid Brazil: a study about the municipality of Cabaceiras/PB
}

ANDRADE ${ }^{1}$, L. G.; RAMOS ${ }^{2}$, N. L.; MORAIS $^{3}$, L. G. B. L;

luciano_guimaraes_123@hotmail.com

\begin{abstract}
Resumo
O geoturismo é um segmento turístico recente, associado aos recursos naturais, especialmente aos aspectos geológicos e geomorfológicos. Desta forma, apresenta-se como atividade econômica bastante promissora. Neste sentido, o presente trabalho aborda o potencial geoturístico do Semiárido paraibano, especificamente do município de Cabaceiras/PB. Tratando-se de um estudo de caso, a pesquisa reúne como ferramentas metodológicas à pesquisa bibliográfica e documental. Como forma de aprofundamento realizou-se ainda, uma pesquisa de campo, na qual objetivou fazer observações sobre o local. Os resultados enaltece um patrimônio geológico bastante diversificado, caracterizado pelas formações rochosas, propício à inserção de atividades turísticas, em especial o geoturismo.
\end{abstract}

Palavras-chave: Geoturismo, Semiárido, Cabaceiras.

\begin{abstract}
Geotourism is a new tourist segment, associated with natural resources, especially geological and geomorphological aspects. Thus, it is presented as a promising economic activity. In this sense, this paper addresses the geotouristic potential of Paraiba Semi-Arid, specifically the city of Cabaceiras / PB. In the case of a case study, the research gathers as methodological tools to bibliographic and documentary research. As a way of deepening held still, field research, which aimed to make comments on the site. The results exalts a very diverse geological heritage, characterized by rock formations, suitable for insertion of tourist activities, especially geotourism.
\end{abstract}

Keywords: Geotourism, Semi-arid, Cabaceiras.

\section{INTRODUÇÃ̃o}

O Brasil possui um quadro natural bastante diversificado, fator significativo para realização de atividades turísticas, principalmente no que tange aos segmentos que utiliza os recursos naturais como alternativa. O Semiárido paraibano apresente um conjunto de potencialidades, proporcionadas pelo ambiente natural e por seu patrimônio histórico-cultural, arqueológico e paleontológico, para o desenvolvimento e aprimoramento do turismo em múltiplas dimensões.

Esse potencial para o desenvolvimento de práticas relacionadas ao turismo é ratificado por Passos (2002) apud Morais et al (2012, p. 660), pois, segundo o autor, “ entre os atrativos naturais da região Semiárida do Brasil, destaca-se: formações rochosas, relevo, clima, hidrografia, solos, vegetação, fauna, enfim a paisagem como um todo; e entre os atrativos histórico-culturais, destacam-se os patrimônios paleontológicos, arqueológicos e arquitetônicos e as manifestações culturais" 
Consoante ao exposto acima, o geoturismo apresenta-se como nova tendência turística, relacionada especialmente aos aspectos geológicos e geomorfológicos. De acordo com NASCIMENTO et al (2008, p.148) pode ser definido como o turismo ecológico com informações e atrativos geológicos. Abrange a descrição de monumentos naturais, parques geológicos, afloramentos de rocha, cachoeiras, cavernas, sítios fossilíferos, paisagens, fontes termais, minas desativadas e outros pontos ou sítios de interesse geológico.

O geoturismo é um segmento que utiliza a geodiversidade como recurso turístico e possui como característica principal a visitação turística a ambientes geológicos, geomorfológico ou paleontológicos dotados de uma qualidade estética ou não, como grutas, formações rochosas, afloramentos de rocha, feições superficiais, conjunto de serras, dentre outros. (MANOSSO, 2010).

Conforme Lopes et al (2011, p.1) "a atividade está pautada em três princípios fundamentais: base no patrimônio geológico, sustentabilidade e na informação geológica”. O geoturismo está relacionado, portanto, com os aspectos geológicos e geomorfológicos e pode ter, basicamente, três motivações: recreação, lazer e aprendizado, todos contribuindo para a conservação de atrativos como quedas d'água, cavernas, afloramentos rochosos, serras, vulcões, jazidas de minerais, cânions, entre outros (BENTO; RODRIGUES, 2001, p.275).

Partindo deste princípio, este trabalho tem como objetivo principal, identificar, caracterizar e discutir o potencial geoturístico do município de Cabaceiras, principalmente no que diz respeito aos seus aspectos naturais, geológicos e geomorfológicos visando contribuir para reflexões sobre a possibilidade de inserção do turismo como alternativa de desenvolvimento local da área estuda.

\section{METODOLOGIA}

Os procedimentos operacionais desta pesquisa foram produzidos a partir do emprego das seguintes metodologias: a revisão bibliográfica de literaturas referente ao assunto em questão, realizadas em livros, teses, dissertações artigos, publicações em periódicos e sites especializados. A pesquisa de campo, com observações e captura de registros fotográficos nos locais de pesquisa que permitiram preservar detalhes para efetivar o objeto de estudo.

Para concretizar o objetivo estabelecido, abordou-se conceitualmente o geoturismo, sendo imprescindível para tanto a caracterização do município de Cabaceiras com intuito de identificar as potencialidades que possibilitem a dinamização da atividade geoturística, considerando os recursos naturais constituindo-se como valores socioeconômicos para a promoção da melhoria de vida das comunidades locais. 
Desse modo, a área de estudo desta pesquisa é delimitada pelo município de Cabaceiras (Figura 1), localizado na microrregião geográfica do Cariri Oriental, na mesorregião geográfica da Borborema, estado da Paraíba.

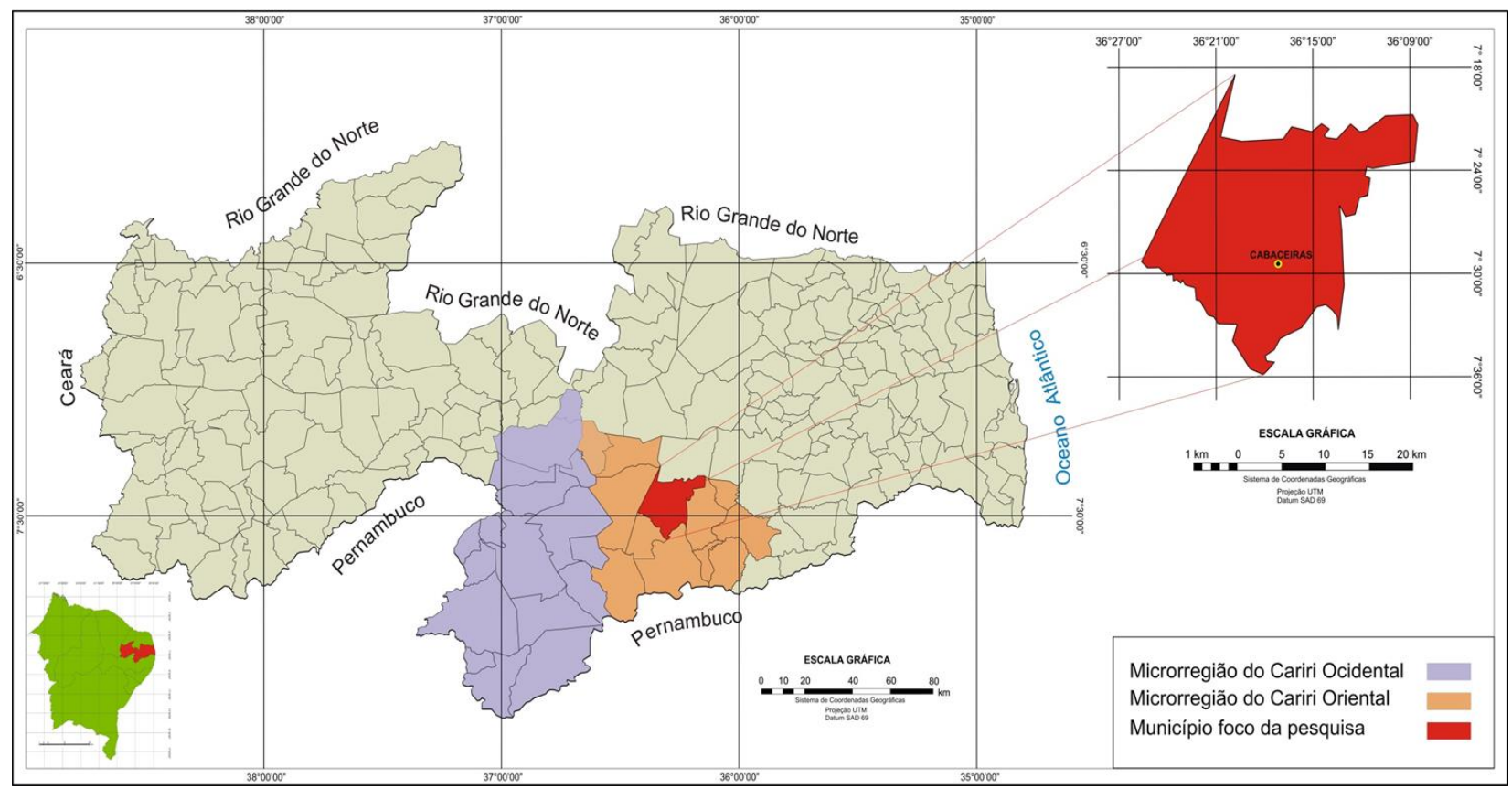

Figura 1: Localização da área estudada. Fonte: IBGE (2009) - Elaborado por MORAIS, 2016.

O município de Cabaceiras possui extensão territorial de aproximadamente 452,922 km². Como principais vias de acesso tem-se as rodovias estaduais PB - 148, que liga Cabaceiras ao município de Queimadas/PB e São João do Cariri/PB e a PB - 160, interligando Cabaceiras ao município de Boa Vista/PB e São Domingos do Cariri/PB. Como relação aos aspectos demográficos, o município de Cabaceiras apresenta população de 5.035 habitantes (IBGE, 2010). De acordo com o PNUD (2010), o município apresenta um Índice de Desenvolvimento Humano IDH de 0,611 .

No que se refere às condições naturais, é possível destacar como elementos comuns, a formação da paisagem, identificados pelo clima quente e seco, semiárido, com temperaturas médias elevadas (aproximadamente $26^{\circ} \mathrm{C}$ ), índices pluviométricos baixos, com registro de médias anuais de aproximadamente de 400 mm/ano (NASCIMENTO; ALVES, 2008).

A área de estudo está localizada na província da Borborema, uma superfície de $380.000 \mathrm{~km}^{2}$ que abrange os estados da Paraíba, Rio Grande do Norte, Sergipe e Ceará, é basicamente coberta por estruturas paleozóicas e mesozóicas, associadas às pequenas bacias tatrogênicas; geradas por reativações de falhas antigas e cujos sedimentos são remanescentes de coberturas mais amplas 
ligadas á primitiva extensão das bacias do Parnaíba e Recôncavo Tucano-jatobá. O relevo cinzento é formado por grandes rochas com aspecto arredondado conhecido como bolderes (CPRM, 2005).

As características acima mencionadas configuram-se como potencial atrativo a realização de práticas turísticas, tornando-se uma alternativa viável de aproveitamento dos recursos naturais, para promover o desenvolvimento local, assim como, a melhoria de vida nas comunidades envolvidas. Diante disso, a próxima seção pretende realizar uma abordagem acerca do potencial natural, principalmente no que tange aos aspectos geológicos, bastante evidentes o quadro natural e sua potencialidade para realização do geoturismo no município de Cabaceiras.

\section{RESULTADOS E DISCUSSÃO}

A partir da abordagem teórica, realizada através de revisão bibliográfica, bem como, a pesquisa de campo, é possível inferir que o município foco desta pesquisa, possui alto potencial para realização de práticas turísticas, especialmente no que se refere ao geoturismo.

No município de Cabaceiras/PB observou-se como principais atrativos para execução do geoturismo os lajedos, que são áreas de afloramento rochoso com blocos e matacões derivados do intemperismo local, onde predomina o tipo físico. Ambos estão situados predominantemente na Área de Preservação Ambiental do Cariri - APA, criada pelo decreto No 25.083 , de 08 de junho, estado da Paraíba (FIALHO et al, 2010). A seguir, observa-se o levantamento dos pontos com potencial para realização do geoturismo no município de Cabaceiras (Figura 2). 


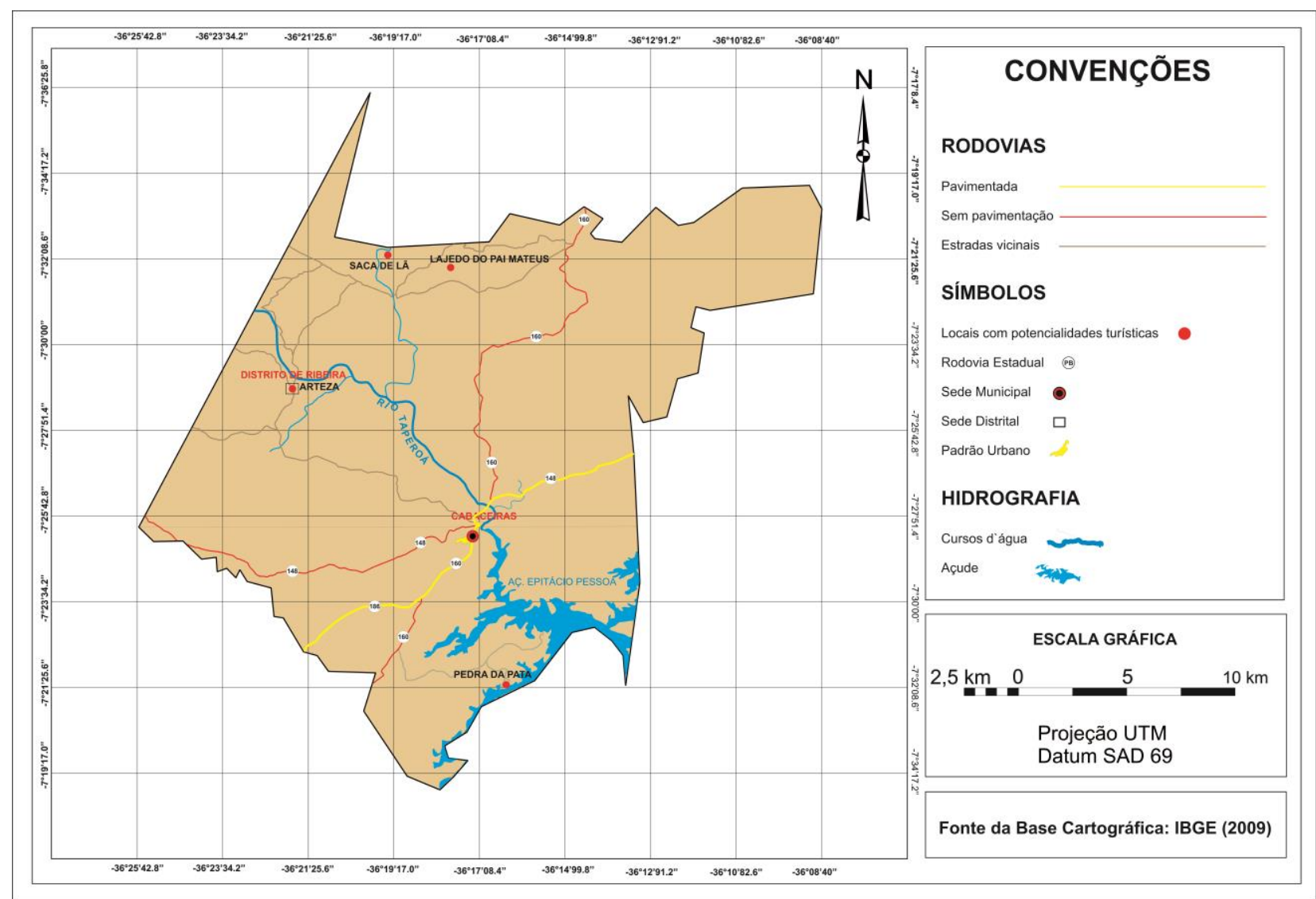

Figura 2 - Localização das areas com potencial para o geoturismo município de Cabaceiras/PB. Fonte: IBGE (2009) - Elaborado por ANDRADE; MORAIS, 2016.

A identificação das áreas com potencial para realização das atividades turísticas permite uma melhor compreensão do patrimônio natural da área estudada, (Figura 2) constituindo como alternativa a promoção do desenvolvimento local, a partir do uso geoturístico, devendo ser valorizados e preservados através da conscientização dos próprios habitantes das comunidades locais, assim como dos visitantes e turistas que buscam o contato com o ambiente natural e sua raríssima beleza.

Entre os destaques identificados, o lajedo de Pai Mateus (Figura 3) é uma formação rochosa, granítica, com aproximadamente de $1 \mathrm{~km}^{2}$ composto por diversos blocos arredondados distribuídos sobre uma base retangular, também de granito (FIALHO et al., 2010). De acordo com Pereira (2008, p.108), “o lajedo de Pai Mateus é, talvez, o elemento natural de maior destaque dos Cariris, não apenas por ter sido utilizado como cenário de filmes e desfile de coleções grifes, mas também por se tratar de uma paisagem deslumbrante". 


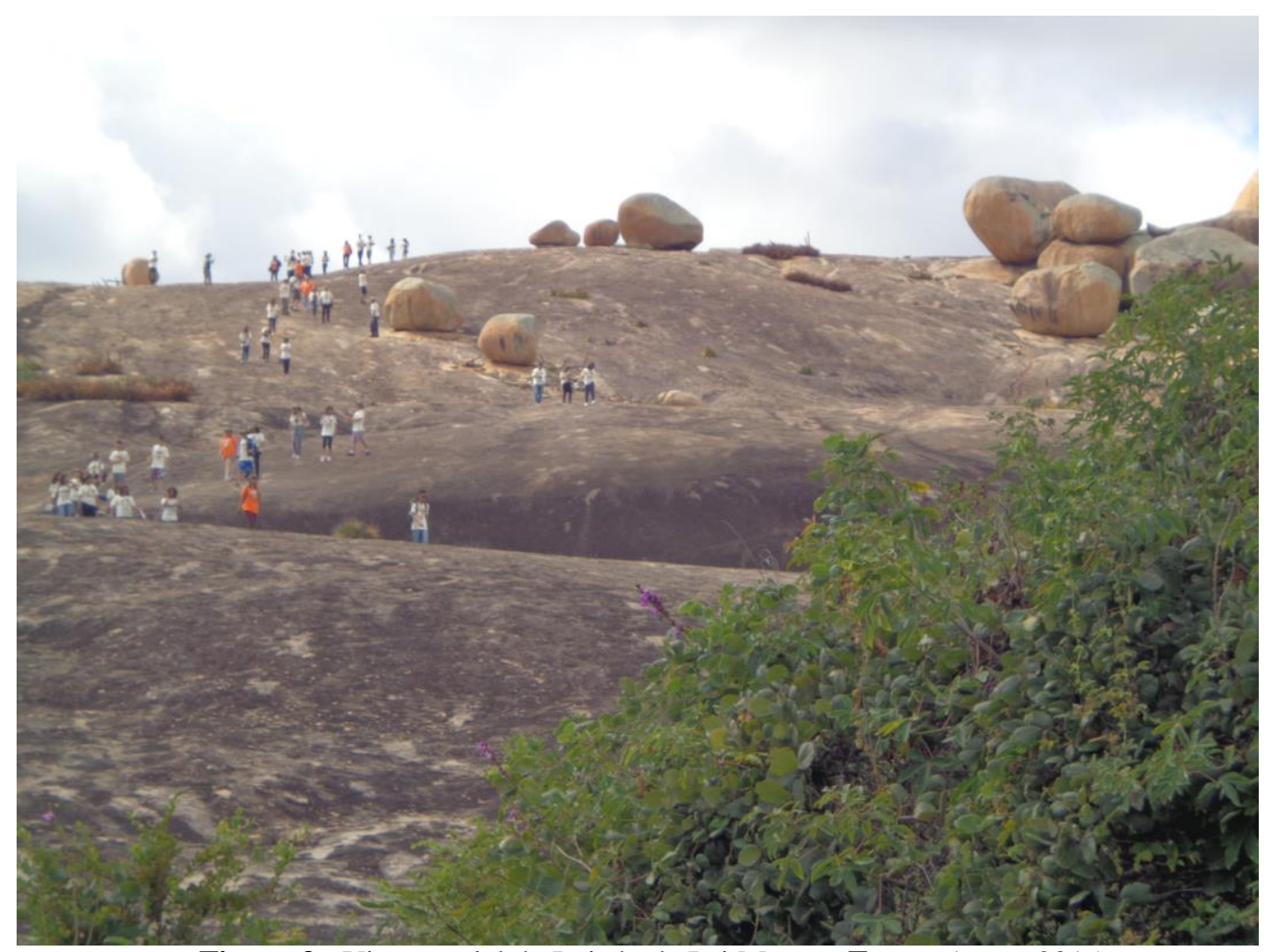

Figura 3 - Vista parcial do Lajedo de Pai Mateus. Fonte: Autor, 2015.

Segundo Lages et al. (2013), a paisagem caracterizada por seus imensos campos de matacões vem sendo formada nos últimos 580 Ma (milhões de anos), passando por inúmeras mudanças provocadas pelos processos geológicos, ação do vento, da chuva e do clima. Assim, as características determinada pelos processos geológicos, a formação rochosa apresenta-se em ótimo estado de conservação, controlada pelos proprietários do Hotel Fazenda Pai Mateus que dispõe de toda estrutura para visitação de mínimo impacto, incluindo guias preparados para atenderem visitantes estrangeiros e conhecedores da geodiversidade e biodiversidade da região (LAGES et al., 2013).

O estímulo e o desenvolvimento do geoturismo por meio da interpretação da paisagem tendem a fomentar o crescimento do número de pessoas sensíveis e interessadas em conhecer e preservar o patrimônio natural tanto dos lugares visitados quanto, de forma mais ampla, dos lugares reconhecidos em qualquer lugar do país e do mundo, obtendo um efeito praticamente instantâneo para a conservação do patrimônio natural e sua geodiversidade (MOURA-FÉ, 2015, p.57).

Próximo ao lajedo de Pai Mateus, a pesquisa pode ainda constatar, a Saca de Lã, monumento geológico constituído por uma formação rochosa que, diferentemente do lajedo de Pai Mateus, é composto por rochas retangulares, sobrepostas formando uma pirâmide com aproximadamente 20 metros de altura (Figura 4). Em razão da semelhança das rochas em relação às sacas cheias de lã de 
algodão que eram muitos comuns na região, o monumento terminou recebendo este nome (FIALHO et.al., 2010).

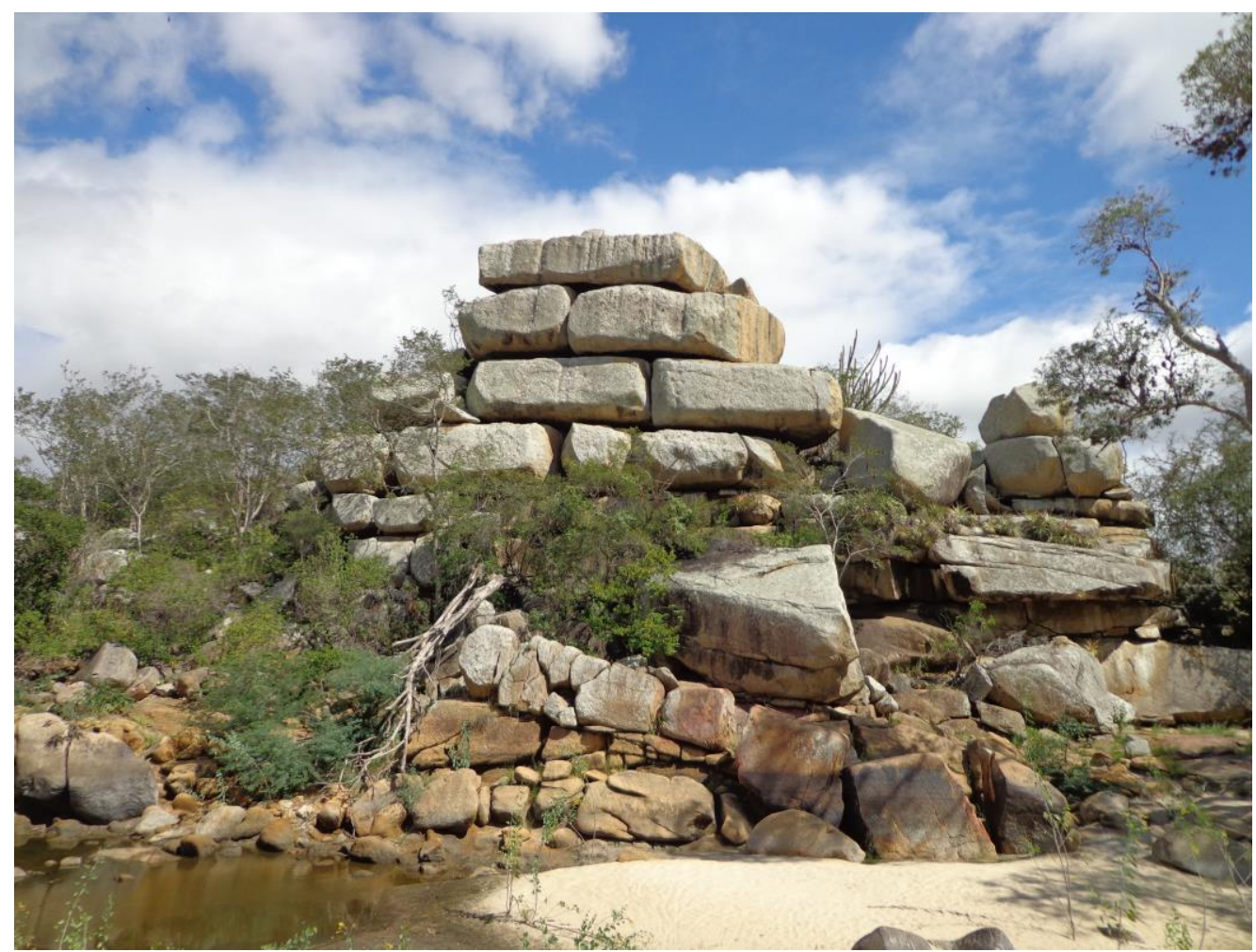

Figura 4 - Vista parcial da Saca de Lã. Fonte: Autor, 2015.

Conforme Lages et al (2013) a Saca de Lã trata-se de uma formação geológica de rara beleza, caracterizando um castle koppie, que são feições de blocos poliédricos empilhados de modo acastelado e cujos vértices e arestas são bem marcados. Sua formação pela preservação do estágio inicial do diaclasamento de fraturas ortogonais fatiados pelas fraturas de alívio sub-horizontais geradas em dimensões regulares. O estágio de clima úmido está bem representado por um matacão solitário que encima este monólito e também por seu interior, onde se encontram grandes blocos vazados que permitem se rastejar sob os mesmos.

Assim, a Saca de Lã, oferece uma alternativa que contempla um aspecto geológico e geomorfológico rico e diversificado, propício a práticas de lazer e aventura, constituindo condições bastante favoráveis a diversas práticas turísticas, principalmente voltadas ao geoturismo. Uma gestão planejada que vislumbre o potencial natural do monumento poderia ampliar a frequência turística da Saca de Lã, tornando-se uma alternativa viável para o desenvolvimento local das comunidades envolvidas.

Desta forma, Lopes et al (2011) infere que o geoturismo promove a geoconservação do patrimônio geológico e envolve as comunidades locais através das atividades econômicas 
sustentáveis, aumentando a oferta de emprego e renda e beneficiando o turista a partir da disponibilização de serviços, produtos e suprimentos.

Outro referencial geoturístico do município de Cabaceiras é a Pedra da pata (Figura 5), situada na confluência dos rios Paraíba e Taperoá, ao sul do município de Cabaceiras. É uma formação rochosa exótica que possibilita um novo referencial geológico do município. O melhoramento dos acessos, além da promoção e divulgação da Pedra da Pata, seriam ações que poderiam potencializar uma maior frequência dos turistas ao monumento.

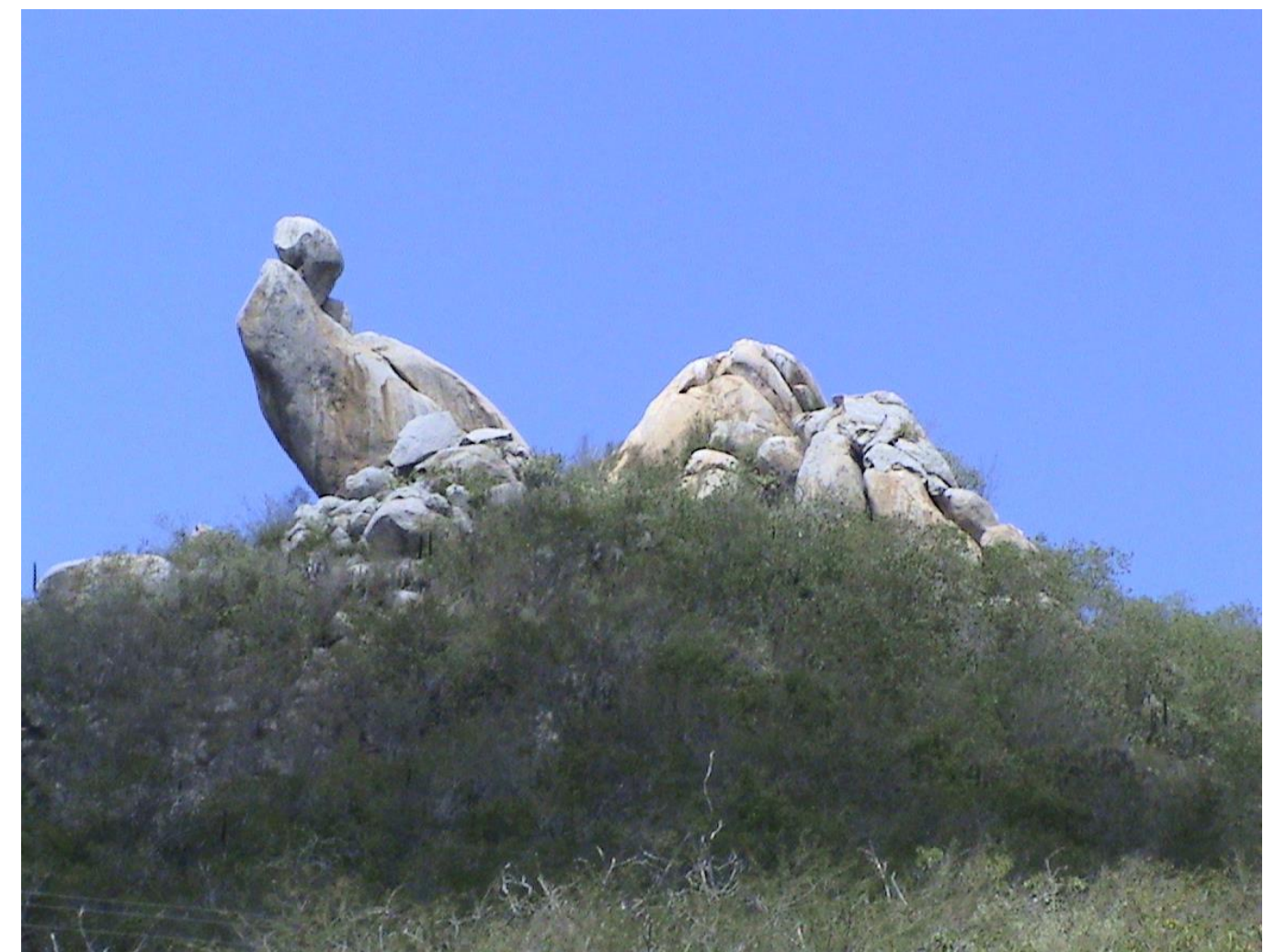

Figura 5 - Visão parcial da formação rochosa Pedra da Pata. Fonte: Autor, 2015.

Pereira (2008, p.103) aponta que "as formações rochosas, testemunhadas pelo relevo residual, se apresentam como atrativos, a exemplo dos Inselbergues, que representam grande potencial destinado aos amantes das trilhas, dos esportes radicais, além de despertar forte interesse de pesquisadores de diferente áreas da ciência”.

Conforme Araújo e Silva (2008, p.67) “é necessário que os locais que ofereçam esse serviço estejam aptos para receber um fluxo de pessoas, o que aumentará a demanda por outros serviços. Para isso, existe a necessidade de investimentos". O melhoramento dos acessos, além da promoção e divulgação da Pedra da Pata, seriam ações que poderiam potencializar uma maior frequência dos turistas ao monumento. 
Para que esta atividade possa desenvolver-se sustentavelmente, é fundamental a participação das comunidades locais e dos turistas na tomada de decisões. Embora seja muitas vezes difícil e demorado envolver todos os interessados no processo de planejamento, essa participação pode trazer benefícios significativos para a sustentabilidade ambiental, incluindo os aspectos sociais, culturais, econômicos e políticos (DOWLING, 2008 apud LOPES et al, 2011).

Conforme Pereira e Melo (2008, p. 11) são ações que precisam ser desenvolvidas, visando o melhor aproveitamento dos potenciais existentes. Ainda sobre a discussão, Araújo e Silva (2008, p.67) afirma que "é necessário que os locais que ofereçam esse serviço estejam aptos para receber um fluxo de pessoas, o que aumentará a demanda por outros serviços.

Deste modo, segundo Moreira (2010), alguns impactos positivos do geoturismo estão relacionados à conservação do patrimônio geológico, geração de empregos diretos e indiretos, a compreensão do ambiente através de uma educação geológica e ambiental dos visitantes, gerando um aumento da consciência da população.

Dessa forma, diante dos desafios encontrados para o desenvolvimento turismo no âmbito do município de Cabaceiras, torna-se necessário uma participação mais efetiva do poder público com vista a promover em conjunto com as comunidades locais, ações integradas para a gestão territorial, geoambiental e para o ordenamento das atividades em diversos segmentos, principalmente no tange ao melhor aproveitamento dos recursos naturais, conforme destacado por este trablho.

\section{CONSIDERAÇÕES FINAIS}

A partir da abordagem estabelecida por este trabalho, avaliando o que foi exposto sobre as potencialidades geoturisticas, considera-se que o Cariri paraibano, no caso do município de Cabaceiras possui um patrimônio natural relevante, podendo contribuir para promoção de turismo em múltiplas dimensões, especificamente através do geoturismo.

A exploração sustentável das belezas naturais através do turismo pode ser uma alternativa de melhoria de vida da população local, devendo ser ordenada por uma gestão territorial e geoambiental adequada, com investimento em infraestrutura, respeito e valorização da cultura local, de modo a não gerar impactos socioambientais negativos para comunidade receptora e ecossistemas locais, potencializando, consequentemente, a geração de fontes e recursos adicionais para garantir a manutenção e preservação dos atrativos locais.

Com uma gestão integrada, realizada através de parcerias, o município de Cabaceiras pode se transformar numa das principais alternativas de atividade turística ligada aos aspectos aqui 
destacados do Semiárido paraibano. Desta forma, podem-se desenvolver atividades com capacidade suficiente para consolidar o turismo de base local.

A execução da atividade turística de forma profissional e planejada poderá gerar resultados econômicos satisfatórios e, ao mesmo tempo, assegurar sua sustentabilidade, através da preservação e conservação dos recursos naturais, especialmente o patrimônio geológico, essencial para as práticas relacionadas ao geoturismo no município de Cabaceiras.

\section{REFERÊNCIAS}

ARAÚJO, S.M.S.; SILVA. E.L. Ecoturismo, desenvolvimento sustentável e planejamento: política brasileira e potencialidades do Sertão Paraibano. Caderno Virtual de Turismo. Rio de Janeiro: UFRJ, 2008

BENTO, L. C. M.; RPDRIGUES, S. C. O geoturismo como instrumento em prol da divulgação, valorização e conservação do patrimônio natural Abiótico - uma reflexão teórica. Turismo e Paisagens Cársticas. Campinas, SeTur/SBE., 3(1), 2010.

DUTRA, José Luís Abreu. Turismo como alternativa de desenvolvimento do semiárido. In: 20 Experiências de Gestão Pública e Cidadania - Ciclo de premiação 2004. São Paulo: Programa Gestão Pública e Cidadania, 2004.

FIALHO, D.A.; ARAÚJO, S.M.S.; BAGNOLI, E. Diagnóstico geoambiental e geoturístico na Área de Proteção Ambiental do Cariri Paraibano. Anais do XVI Encontro Nacional de Geógrafos, Porto Alegre, 2010. ISBN 978-85-99907-02-3. p. 01 - 10.

IBGE. INSTITUTO BRASILEIRO DE GEOGRAFIA E ESTATISTICA. Senso demográfico 2010. Disponível em: http://www.cidades.ibge.gov.br. Acessado em 20 de junho de 2016.

CPRM - Serviço Geológico do Brasil. Projeto cadastro de fontes de abastecimento por água subterrânea. Diagnóstico do município de Cabaceiras - PB. MASCARENHAS, J.C.; BELTRÃ̃O, B.A.; SOUZA JUNIOR, L.C.; MORAIS, F.; MENDES, V.A.; MIRANDA, J.L.F. (org.) Recife: CPRM/PRODEEM, 10p. e anexos. 2005.

LAGES, G. A.; MARINHO, M. S.; NASCIMENTO, M. A. L.; MEDEIROS, V. C.; DANTAS, E. L.; FIALHO, D. A. Mar de Bolas do Lajedo do Pai Mateus, Cabaceiras, PB - Campo de matacões graníticos gigantes e registros rupestres de civilização pré-colombiana. In: Winge, M.; Schobbenhaus, C.; Souza, C. R. G.; Fernandes, A. C. S.; Berbert-Born, M.; Sallunfilho, W.; Queiroz, E. T. (Edit.). Sítios Geológicos e Paleontológicos do Brasil. Publicado na Internet em 01/05/2013 no endereço http://sigep.cprm.gov.br/sitio068/sitio068.pdf

LOPES, L.S. O.; ARAÚJO, J. L.; CASTRO, A. J. F. Geoturismo: Estratégia de Geoconservação e de Desenvolvimento Local. Caderno de Geografia, v.21, n.35, 2011. ISSN 0103-8427. p. 01 - 11.

MANOSSO, F. C. Geodiversidade e Geoturismo: o potencial da Serra do Cadeado-PR. Anais do VI Seminário de Pesquisa em Turismo do MERCOSUL - Caxias do Sul, 9 e 10 de julho de 2010. ISSN 1806 -0447. 
MORAIS, L. G. B. L.; SILVA, O. J.; ALMEIDA, C. A. de. Trabalhando o turismo no contexto escolar: reflexões a partir de experiência no ensino de geografia no município de São João do Cariri (Paraíba/PB, Brasil). In: Turismo \& Sociedade. Curitiba, v. 6, n. 3, p. 531-551, jul. 2013.

. São João do Cariri - sua muralha de pedra: aspectos ambientais e potencialidades turísticas. In: SEABRA, Giovanni (Org.). Comunidades, Natureza e Cultura no Turismo. João Pessoa: Editora Universitária da UFPB, 2012.

MOREIRA,J.C. Geoturismo: uma abordagem histórico-conceitual. Turismo e Paisagens Cársticas. Campinas, SeTur/SBE., 3(1), 2010.

MOURA-FÉ, M.M. Geoturismo: uma proposta de turismo sustentável e conservacionista para a Região Nordeste do Brasil. Sociedade \& Natureza. Uberlândia, 27 (1): 53-66, jan/abr/2015.

NASCIMENTO, S.S.; ALVES J.J.A. Ecoclimatologia do Cariri Paraibano. Revista Geográfica Acadêmica. v. 2 n. 3, p. 28-41, 2008.

NASCIMENTO, M. A. L.; SHOBBENHAUS, C.; MEDINA, A. I. de M. Patrimônio geológico: turismo sustentável. In: SILVA, C. R. da (Ed.). Geodiversidade do Brasil - conhecer o passado para entender o presente e prever o futuro. [s.l.]: CPRM, 2009. p. $147-162$.

PEREIRA, R. A. Turismo e desenvolvimento local nos Cariris Velhos: uma alternativa à melhoria da qualidade de vida no semi-árido. Caminhos de Geografia, Uberlândia, v. 9, n. 28, p. 96-113, dez. 2008.

; MELO, J. A. B. de. Ecoturismo nos Cariris Velhos: uma possiblidade de reestruturação socioeconômica para o Semi-árido brasileiro. Global Tourism, v. 4, n.1, p. 01-14, mai. 2008.

Recebido em: 14/08/2016

Aceito para publicação em: 01/10/2016 